\title{
Research on the Application of Mixed Media in Watercolor Painting
}

\author{
Lijun Yi \\ Sichuan Fine Arts Institute \\ Chongqing, China
}

\begin{abstract}
From the watercolor painting exhibitions in recent years, it can be found that the application of mixed media in watercolor painting is wider and wider. Modern watercolor is not limited in the pure using of the single medium of pen and pigment in painting. The application of multi mixed media has enriched the language of watercolor art, and also enhanced the expression force and appeal of watercolor painting. More and more artists are using mixed media, which will certainly have an effect on the techniques and the form of artistic work. This thesis centers on the research of the application of mixed media in watercolor painting, aiming to provide references.
\end{abstract}

Keywords $\longrightarrow$ mixed media; watercolor painting; application

\section{INTRODUCTION ON RELATED TERMS}

\section{A. Introduction}

Watercolor painting can be defined from two perspectives, the broad sense and the narrow sense.

1) Definition of watercolor painting in the narrow sense: In Encyclopedia of China, watercolor painting is defined like this: "the painting being painted by watercolor pigment mixed with water. Watercolor painting came into being in Europe at the end of 15th century, became an independent painting type after the 18th century, and was introduced into China at the beginning of 20th century. Famous British watercolor artists includes J.M.W. Turner and John Constable, etc.. There are also a large number of excellent watercolor artists and watercolor paintings in China. The techniques of watercolor painting includes dry drawing method, wet drawing method, immerse connecting method, stippling method, color rendering method, and washing method and so on. Watercolor painting reflects the shades and transparency of color through water, displaying special artistic effects like bright, transparent, light, moist, and vivid and so on by covering and integration of paper and pigment." From the narrow sense, watercolor painting is the way of painting on watercolor paper using watercolor pigment by the dilution medium of water.

2) Definition of watercolor painting in the broad sense: Because of the highly advanced coal industry and various kinds of pigments and many other reasons, techniques and definition of contemporary watercolor painting is not as in the narrow sense defined in encyclopedia. The definition of watercolor painting in the broad sense is as following: "as long as water is used as medium to dilute color pigments like propylene, ink, water soluble pencil and so on, the painting thus painted can be called watercolor, and is included in the field of watercolor painting." Like other painting style, watercolor painting in the broad sense is also extremely inclusive, with various artistic features, and can not be judged by a certain type. Whether artist's style is vivid and transparent or dignified and uncomplicated, those are all the personal monologue of the artist and are about his own artistic pursuit.

\section{B. Definition of Mixed Media}

"Mixed Media" in western countries refers that using all kinds of media and material to enrich visual expression in the painting, including material of different qualities and forms. Morris Cohen regards that "we are surrounded by media". Mixed media in art history came into being after the producing of cubism painting in the 20th century. It emphasizes the authenticity and falsity of painting, mixed various media into painting. That is to say, mixed media includes a wide range of materials. In painting, it is no longer limited to the basic materials of various painting like carrier, pigment, pen and so on, it has extended to natural media, industry products, daily disposals, chemicals like clay, glass, cigarette end, chemical reagent and so on. Watercolor mixed media painting includes all the materials that enable to combine watercolor language or suitable to express watercolor painting. Watercolor works using different media to express different style and feature, which is different from traditional watercolor in form and content, can improve the comprehensive expressive force of watercolor works.

\section{ANALYSIS ON THE REASONS OF APPLYING MIXED MEDIA IN WATERCOLOR PAINTING}

In today's world, paints can be classified into two nature, oil paint and water paint. Water is the most important media of water paint that all need to be mixed with water. We can say that watercolor paint and Chinese painting pigment all belong to water paint with same property. After the dilution of watercolor pigment, though the painting with smooth, transparent and water color blends effects can be achieved, it would be too pale and simple in reflect saturation and strength. In the meantime, watercolor paint cannot be painted repeatedly, especially for the dark part of the painting; repeated revision 
would result to dirty picture while saturate color painting without stopping would be not transparent. However, reflecting on other opacity paints like oil painting, the picture can be covered without limitation and still can achieve rich color effects. Especially that the white color in oil paint can be mixed with any other color to produce extremely rich and colorful gray tone. These are all the aspects that watercolor paint cannot match.

Another important material of watercolor painting is watercolor paper, which is also less than satisfactory. Watercolor paper in the present market cannot bear the repeatedly paint and wash. Imported paper, with relative better quality, still cannot stand the long time repetition of large creation. Though there are many examples of successful creations that finished without stopping, much more works that deserve high praise are polished and revised many times. If a piece of paper can bear more times of washing and revision, the possibility of succeeding for the painting would be higher. On the other hand, another unavoidable problem of watercolor paper is not easy to preserve. In collection field and auction market, it is an unquestioned fact that the price of watercolor painting is not high. It is also the domestic condition that most capable painters are unwilling to paint watercolor, one major reason is that the gradually gray watercolor paper would affect the original color of the painting. Keep on finding better media is almost the same route of each kind of art. It has taken centuries for westerners to solve the oil of oil paintings. At present, there are much wider and more types of media from different fields to choose. Many artists have started practices of crossing different arts fields, making up for each material's deficiencies and mixed use since long. To summarize, "painting to be more comprehensive" have become a fact in some levels, including watercolor painting of course.

\section{APPLICATION OF MiXED MEDIA IN WATERCOLOR PAINTING}

\section{A. Experiment on Mixed Media}

1) Propylene light texture modeling gel: Propylene light texture modeling gel is a kind of semi-transparent material that shapes the texture effect of the picture. With strong adhesive force and good flexibility, it is better than normal modeling cream that can paint relief-like texture, no crack and no shed. When applied in relatively thin modeling, it can achieve transparent yet profound effects. When applied in thick modeling, it looks semi-transparent. It can be used mixing with watercolor paint, gel, propylene pigment and other materials. Under wet condition, painting knife can be used to portray cutting-like texture, and can be carved and modified after drying. It can also be mixed with propylene pigment to produce effects of different levels, and can be over painted with watercolor pigment and polished after drying. When mixed with watercolor paint, it can produce evenly oil painting-like effect, being applied to large area tile background and can also produce texture effect of mountain and stone.

2) Modeling Cream: Modeling cream belongs to white water primer, originally used as the backing material of oil painting, which features are thick, easy to be pile up, strong adhesive force, and quick-drying without crack. With these features, it is mixed with watercolor paint. First, fetch modeling cream with scraping knife directly and paint on watercolor paper, and then shape texture in any form. Make the modeling cream smooth, over paint with watercolor paint after it is dried totally, and thus watercolor can float above it, producing even effect. The modeling cream might be painted unevenly, over paint with watercolor paint after it is dried totally, and thus produce mottled and uneven effects, making the painting rich with different layers.

3) Sand and abrasive paper: Sand is also widely used in watercolor painting in any part of the picture (including background and major object). It is pretty good in modeling the texture of object and picture.

4) Propylene rough texture structural adhesive: This kind of adhesive contains particles that can produce crystal-like effect. It is also mixed with watercolor paint after dried totally to produce mottled effect. This kind of mottled effect, which is essentially different from the mottled effect produced by propylene light texture modeling gel and modeling cream, carries small particles and looks like suede surface from distance. This cannot be matched by any other material. The adhesive can also be piled thickly and then shaped with scraping knife.

5) Coalescing agent and styrene acrylic emulsion: Coalescing agent and styrene acrylic emulsion are all chemical materials; blending them into watercolor painting will produce rich picture effects. When these two materials are used together, the effect produced would be different with different blending proportion. The effect produced after blending watercolor paint into the mixture is dignified and with cracks, suitable to describe large background or in abstract manner.

\section{B. Application of Mixed Media in Watercolor Painting}

The application of mixed media in painting can be found as early as in works of Picasso, and Braque in the early 20th century. The application of mixed media in watercolor painting also started very early. The famous American watercolor painter Wyeth added a certain proportion of egg yolk in watercolor paint changed the feature that the dark part of watercolor is easy to be dirty and produced interesting texture effects, and also enable more changes in the painting of details in the meantime. The watercolor paintings of Wyeth we saw are thick and in detail like oil painting. Many watercolor painters in domestic painting circle have made referential achievements in applying mixed media in the creation of watercolor painting. Some artists tried to paint a thin layer of white propylene paint in watercolor paper as the bottom layer. Watercolor paper processed by white propylene paint is more durable that can be washed and revised repeatedly. The difference is that the water-absorbing quality of paper is changed. Mr. Wang Zengyan has put the watercolor painting with both processed and unprocessed watercolor paper under the same sunshine for about half a year, while the former remained bright color and the later became yellowing and dark 
as we mentioned before. Later, process watercolor paper with a bottom layer has become a custom, lithopone and white latex, as well as some chemical agents all have become the tentative media of some artists. Of course, the new attempts and pursuits are not only for prolonging the using time of paper, but also in the pursuit of extremely attractive texture effects.

\section{PRACTICAL SignificANCE OF APPLYING MiXed MEdia IN WATERCOLOR PAINTING}

Under macro artistic environment, watercolor art is developing continuously. Artists are also seeking new painting materials and innovating painting techniques constantly, with the aim of expanding the concept of watercolor painting. The research on and application of mixed media greatly enriched the artistic language of watercolor painting and also strengthen the reference and integration between watercolor and other artistic types and other subjects, expanding watercolor artists' vision and thinking method in developing watercolor art and providing a steady flow of material for artists to express themselves.

\section{CONCLUSION}

Media is the basis of artistic expression, which is undeniable as the essential element of artistic expression. Under the subject of serving watercolor creation, any kind of media can be used as long as it can bring the desired effect to the painter. Watercolor paint, Chinese painting paint, propylene paint, and slide water and so on can all be used as paints and being painted on paper randomly. Whether painting form or media, they all developed along with the development of times, and even richer materials will be found in the future. In the application of media, it needs our brave exploration and bold attempt. Relying on the precious experience and his own creation, media can be further expanded and the new direction of painting can be found, creating a bright future on the basis of inheriting tradition.

\section{REFERENCES}

[1] Dong Wenjing. Spiritual Definition of Mixed Media in Watercolor Creation [J]. Art Science and Technology, 2013,26(6):2

[2] Guo Xiaobao. Discussion on Re-recognition of Senior High School Watercolor Painting Teaching [J]. Educational Circles: Comprehensive Education and Research, 2015(7):180

[3] Zhang Wei. Guidance on Children Watercolor Painting Creation [J]. Inner Mongolian Education, 2014(22):70-71

[4] Dou Fengzhi. Innovation on Contemporary Watercolor Teaching [J]. Culture Monthly: Periodical of Cultural Industry, 2014(2):74-75

[5] Teng Long, Liu Hu. Discussion on the Problems in the Development Process of Propylene Paint [J]. Beauty and Times: City, 2014(2):123 